\title{
Divergências conceituais em torno da comunicação popular e comunitária na América Latina ${ }^{1}$
}

\author{
Beatriz Dornelles ${ }^{2}$ \\ PUCRS
}

\begin{abstract}
RESUMO: Este artigo propõe-se a rever a discussão estabelecida por alguns autores latino-americanos, com ênfase nos brasileiros, em torno de características da comunicação popular, também chamada de participativa ou comunitária, entre outras denominações atribuídas entre 1960 e 1980. Objetivamos contribuir para uma melhor compreensão, em termos de atualidade, das expressões comunicação popular, jornal popular, jornalismo popular, jornal comunitário. Atualizamos a discussão até os dias atuais, acrescentando novos conceitos disseminados a partir de 1980.
\end{abstract}

Palavras-chave: comunicação popular, jornalismo popular, jornal popular, jornal comunitário.

ABSTRACT: This article brings up reflections and concepts that were created by researchers in Latin America in order to define Popular Communication (participatory and communitarian) and others denominations which were established between 1960 and 1980. We intend to contribute towards a better understanding of those concepts, taking in to account changes which took place in expressions like popular communication, popular newspaper, popular journalism and communitarian newspaper. We bring up to our days the discussion about those themes, adding up news concepts disseminated in our academic circles.

Key Words: popular communication, communitarian newspaper, popular journalism, popular newspaper.

\footnotetext{
${ }^{1}$ Este artigo é fruto da pesquisa intitulada Retratos de Porto Alegre, através da imprensa de bairro, financiado pelo CNPq, tendo como bolsista a estudante de Jornalismo Alessandra Scangarelli Brites $/ 5^{\circ}$ semestre. A imprensa de bairro e comunitária estão sendo analisadas e categorizadas pela autora deste, de acordo com características que hora se assemelham às características da imprensa popular, ora se confundem com a comunitária.

2 Professora Dra. do Programa de Pós-Graduação da Faculdade de Comunicação Social (Famecos) da Pontifícia Universidade Católica do Rio Grande do Sul (PUCRS), Brasil.
} 
Resumen: Este artículo se propone rediscutir el debate establecido por algunos estudiosos latinoamericanos, con encase nos brasileros, en torno de las características de la Comunicación Popular, también llamada de participativa y comunitaria, entre otras denominaciones atribuidas entre los años de 1960 a 1980. Objetivamos contribuir para una mejor comprensión, en termos de actualidad, de las expresiones Comunicación popular, periódico popular, periodismo popular y periódico comunitario. Actualizamos la discusión hasta los días actuales, acrecentando novos conceptos difundidos después de 1980.

Palabras-claves: comunicación popular, comunicación comunitaria, prensa popular, prensa comunitaria, prensa alternativa.

As Comunidades Eclesiais de Base (CEBs) deram início na América Latina a um novo fazer popular, no final dos anos 6o, discutindo os problemas que dizem respeito à vida da comunidade, de religiosos ou não, e ampliando a discussão para debates sociais e políticos. Assim, ocorreu o surgimento de uma nova palavra, formando uma rede de comunicação popular.

Essa comunicação era produzida, considerando a realidade da comunidade. $\mathrm{Na}$ estrutura anterior aos anos 6o, as classes populares eram vistas como uma grande massa sem voz nem forma. Na nova relação houve significativas mudanças na cultura comunicacional. Esse tema foi amplamente explorado e pesquisado por Pedro Gilberto Gomes, em sua tese de doutorado, na USP, quando dissertou sobre a polêmica em torno do conceito de Comunicação Popular. Posteriormente, em 1990, publicou o livro "Jornalismo Alternativo no projeto popular", contendo a essência de sua tese. E também pela pesquisadora Regina Festa, em sua tese de doutorado, intitulada "Comunicação Popular e Alternativa. A realidade e as utopias (1984)". 
No mesmo período (1989), a pesquisadora Christa Berger ${ }^{3}$, na época professora da UFRGS, realizou um minucioso levantamento sobre "comunicação popular e/ou alternativa no Brasil”, tendo observado imprecisão do conceito e falta de definição consensual em torno do tema. Nesse trabalho, organizou um levantamento das obras mais significativas sobre o tema no Brasil, tendo levantado 15 autores brasileiros de livros que versam sobre comunicação popular e comunicação alternativa, e 22 autores brasileiros que escreveram sobre imprensa alternativa, além de rastrear a bibliografia latino-americana.

Mesmo tendo se passado 18 anos, até hoje não encontramos consenso sobre o tema entre os pesquisadores da área. Assim, pretendemos apresentar nesse trabalho as várias posições em torno do assunto, valendo-nos, especialmente, dos estudos realizados por Gomes, Festa e Berger, e trazendo a discussão para a atualidade, a partir de outros autores que surgiram nos últimos 17 anos.

Dentro da busca de uma estrutura teórica para as questões que envolvem a Comunicação Popular e sua definição, encontramos em Luiz Ramiro Beltrán (1981) um modelo teórico como objeto de discussão:

[...] Comunicação é o processo de interação social democrático baseado no intercâmbio de símbolos mediante os quais os seres humanos compartilham voluntariamente suas experiências sob condições de acesso livre e igualitário, diálogo e participação. Todos têm direito à comunicação com o propósito de satisfazer suas necessidades de comunicação por meio da utilização dos recursos da comunicação.

Os seres humanos comunicam-se com múltiplos propósitos. O principal não é o exercício de influência sobre o comportamento dos outros (p. 65).

Beltrán defendeu a tese de que a "comunicação horizontal" seria mais fácil de ser estabelecida nos "modelos interpessoais do que no caso dos modelos impessoais". Para Gomes (1990, p. 28), esta explicação está ligada ao "problema da técnica: dificuldade em haver retroalimentação nos meios de massa”. Na sua maioria, os meios de comunicação de massa são "instrumentos viciados das forças conservadoras e mercantilistas". Teoricamente, toda comunicação deveria ser horizontal, mas nem sempre este processo acontece na prática.

3 Christa Berger é hoje professora e coordenadora do Programa de Pós-Graduação em Comunicação da Unisinos. 
A comunicação vertical foi descrita por Beltrán (Ibid., p. 72) da seguinte forma:

(...) o que ocorre seguidamente sob o nome de comunicação é pouco mais do que um monólogo dominante em benefício do iniciador do processo. A retroalimentação não é empregada para proporcionar a oportunidade de um diálogo autêntico. O receptor das mensagens é passivo e está submetido, uma vez que quase nunca se lhe dá a oportunidade adequada para atuar também como verdadeiro e livre emissor; seu papel consiste em escutar e obedecer. Tão vertical, assimétrica e quase autoritária relação social constitui, no meu modo de ver, uma forma antidemocrática de comunicação (...). Devemos ser capazes de construir um novo conceito de comunicação - um modelo humanizado, não elitista, democrático e não-mercantilista.

Beltrán desenvolveu a proposição de um modelo de comunicação horizontal a partir de três pilares: exercício efetivo do direito de receber mensagens; exercício efetivo do direito de transmitir mensagens e o exercício do direito de tomar parte no processo de produção e transmissão das mensagens. Essas proposições foram incorporadas ao discurso e às práticas de instituições ligadas à comunicação popular e alternativa, como foi o caso das igrejas e de organizações não-governamentais. A proposta contribuiu para a consolidação da proposta de comunicação horizontal, que se tornou conhecida na América Latina pelo nome de comunicação popular, participativa ou alternativa.

A participação popular, segundo os autores, acontece na comunicação quando ambos interlocutores têm a mesma oportunidade de gerar suas próprias mensagens. Um sistema de comunicação pode ser considerado participativo se prevê mecanismos e canais que permitam aos grupos de base determinar com independência os conteúdos temáticos do programa e emitir mensagens autônomas, surgidas deles mesmos e não escolhidas pelos promotores; torna-se possível que os setores populares falem daquilo que eles próprios querem falar.

Para Kaplun (1983), as três dimensões da participação (educacional, comunicacional, social e política) têm a democratização como forte apelo. E completa, dizendo que "esta nova concepção da comunicação educativa, participatória e associada à organização popular propõe-se contribuir para democratizar, ao mesmo tempo, a educação, a comunicação e o conjunto das relações sociais". 
Não é fácil, no entanto, definir o que é Comunicação Popular, usada praticamente como sinônimo de Comunicação Comunitária, Comunicação Participativa, Comunicação Alternativa, Comunicação Dialógica (horizontal) etc. Regina Festa (1986) identificou 33 tentativas de definir comunicação popular e/ou alternativa na América Latina.

Gomes observou que o "conceito alternativo" parece apontar para uma contraposição à comunicação massiva, enquanto que o "conceito popular" diz respeito à inserção num contexto alternativo de luta que visa estabelecer uma nova sociedade a partir da ótica das classes populares. Berger (1989) observa que o ponto comum entre os autores está no objetivo: "a outra comunicação busca transformar a Comunicação de Massa, para que as classes e os grupos dominados tomem a palavra e alcancem uma sociedade mais justa” (p. 14).

Beltrán (1981) entende que a comunicação popular é aquela que se insere num contexto alternativo que é o do "enfrentamento com o projeto de dominação capitalista e nele define-se como agente de definição do projeto popular”. Para definir Comunicação Popular, diferentes autores apontaram diferentes características, as quais estão sendo empregadas pelos pesquisadores da área em diversos cursos de comunicação da América Latina. Vejamos alguns:

Para Gilberto Gimenez (1978), a Comunicação Popular é um tipo de comunicação que tem a ver com o povo. No seu entender, dentro da visão romântica de povo, assumida pela esquerda latino-americana, povo é o sujeito protagonista da história, dentro do populismo terceiro-mundista.

Desta maneira, o autor entende por povo "o conjunto das classes subalternas e instrumentalizadas submetidas à dominação econômica e política das classes hegemônicas dentro de uma determinada sociedade” (p. 98). Para ser Comunicação Popular é necessário, ao menos, tendencialmente, a quebra da lógica da dominação e se realiza a partir do próprio povo, compartilhando, o quanto possível, seus próprios códigos. A identificação entre Comunicação Popular e Comunicação Emancipadora está no fato de que toda Comunicação, para ser Popular, deve ser Emancipadora.

Felipe Espinosa (1978) considerou ineficaz a Comunicação Popular, por se apresentar com muita teoria e pouca prática. Para ele, a Comunicação será 
libertadora quando o povo expressar, com sua própria voz, os seus próprios valores e sua visão de mundo. Espinosa (Ibidem) entende que a Comunicação está dentro de um quadro de constante manipulação e controle dos meios de comunicação pelas classes dominantes. Daí que os próprios receptores têm introjetados uma ideologia reacionária. O papel da Comunicação seria organizar o que estava disperso, valorizando os elementos progressistas que subsistem no povo. Propôs unir a teoria com os aspectos progressistas da cultura popular.

Francisco Vanderhoff (1978) procurou relacionar a Comunicação Popular e a evangelização, vinculando a primeira à realidade social existente. Enfatizou que as possibilidades da Comunicação Popular estavam "condicionadas pela capacidade criativa das classes subalternas para elaborar condições cada vez mais hábeis e autônomas que contraponham as limitações que a cultura hegemônica trata de impor-lhe (p. 36-40)”.

Maria Cristina Mata (1990) considera que a Comunicação Popular é uma comunicação levada a cabo pelos setores dominados de nosso continente. Por setores entende-se as classes subalternas, submetidas à exploração econômica e ao domínio político e cultural por parte dos setores hegemônicos de cada sociedade. Para Mata (Idem), a comunicação popular serve como instrumento dos setores dominados para expressar a sua situação, analisando-a, bem como a expressão do novo tipo de relações sociais que essas práticas geram: horizontais, dialógicas, participativas.

José Martinez Terrero (1982) entende que a Comunicação Popular tem muitos níveis e graus, sendo que o mais completo é a comunicação popular transformadora de estruturas. A produção de meios de comunicação pode ser para, com ou do povo. No seu entender, a Comunicação Popular faz parte da cultura popular e exerce várias funções: a destruição radical da ideologia dominante; a construção histórica da ideologia da classe dominada a partir de diversas táticas de comunicação popular: ser voz dos sem voz e devolver a fala ao povo; construção do povo como sujeito histórico, social e político.

Na visão de Terrero (Ibid., p. 45), "o que faz com que uma comunicação seja popular é sua inserção num contexto alternativo, de forma a potencializá-lo”. Um 
contexto alternativo caracteriza-se por sua tendência a romper a ordem do capital, a integrar aquilo que o capital fragmenta.

Hérnan Matinez Pardo (1982) registrou que a Comunicação Popular existe quando o código é popular, quando a sua linguagem é popular, quando sua mensagem se opõe à comunicação burguesa. Ressaltou, no entanto, que não se pode considerar o processo da Comunicação como algo isolado. Tanto emissor, quanto o receptor são produzidos socialmente. Deste modo, não se pode isolar o processo como uma luta entre a comunicação popular e a comunicação burguesa, pois a luta não é essa. Sua luta é a "favor de algo" e não "contra algo".

Pedro Gilberto Gomes reflete sobre o significado de "comunicação alternativa" e a define a partir da conceituação de "contexto alternativo", de Pardo (Ibid.): caracteriza-se por sua tendência a romper a ordem do capital, a integrar o que o capital fragmenta; caracteriza-se por romper os limites que o capital coloca e seus mecanismos, que impedem a participação efetiva na produção do conhecimento e da sociedade.

Como se observa, o contexto, para Pardo, tem um importante papel na determinação da comunicação popular. A mesma posição é compartilhada por Regina Festa, que depois de avaliar vários autores, concluiu: “A comunicação popular refere-se ao modo de expressão das classes populares de acordo com a sua capacidade de atuar sobre o contexto social na qual ela se reproduz" (1986, p.30). Para ela, o contexto é de enfrentamento com o projeto de dominação capitalista, no qual a comunicação popular é o agente do projeto popular, que vai conformando a inter-relação entre grupos e classes populares.

Gomes não concorda com essas definições. Para ele, o contexto "alternativo" não é a "comunicação alternativa”, mas apenas o que torna uma comunicação popular. “Cabe dizer que o 'conceito alternativo' parece apontar para uma contraposição à comunicação massiva, enquanto que o 'conceito popular' diz respeito à inserção num contexto alternativo de luta que visa estabelecer uma nova sociedade a partir da ótica das classes populares".

Após análise de vários autores, Gomes acaba optando pelo modelo apresentado por Luiz Ramirez Beltrán (1981): Comunicação Popular é aquela que, 
inserida num contexto alternativo, contribui para a luta por uma transformação social efetiva. Portanto, a Comunicação Popular é aquela que se insere num contexto alternativo que é o do enfrentamento com o projeto de dominação capitalista e nele define-se como agente de definição do projeto popular. Também compreendendo deste modo a Comunicação Popular, poder-se-á perceber como o projeto popular de transformação social se utiliza da comunicação em geral, e do jornalismo em particular, para viabilizar as suas lutas e anseios.

No final dos anos 90, a obra intitulada "Comunicação nos Movimentos Populares - A participação na construção da cidadania”, de Cicília Maria Krohling Peruzzo (1998), dá uma contribuição valiosa aos estudiosos da área. A autora, conforme observou Luiz Eduardo Wanderley (In: PERUZZO, 1998)4 no prefácio da obra citada, faz uma sistematização da bibliografia referente ao tema. "O trabalho objetiva dirigir a reflexão tendo em vista a participação popular na comunicação como um elemento significativo na ampliação da cidadania, a qual também se busca discutir teoricamente (p. 17)".

Wanderley (Ibid.) com muita precisão chama atenção para um ponto crucial em torno do assunto:

Há um intenso debate sobre a conceituação de popular, considerando as transformações engendradas pelo desenvolvimento do capitalismo mundial tanto nos países centrais quanto nos periféricos, ocasionando a irrupção de novas estratificações na esfera societária, dificuldades adicionais de ampliar ou encolher a sua abrangência em função de captar o fenômeno da exclusão, de situar as novas categorias de trabalhadores, de mapear o setor de serviços, de classificar o lugar ocupado pela classe operária na divisão social do trabalho. Faz-se necessária, pois, uma investigação mais fina, que explicite com maior rigor o que seja popular na atual conjuntura, especialmente na América Latina (p. 18).

A considerar nossas pesquisas, a necessidade de explicitação do popular continua sendo uma realidade até os dias atuais. Se, por um lado, Peruzzo (Ibid.) não pôde realizar uma investigação mais fina para definir popular, por outro apresentou argumentos convincentes sobre a inadequação de características que definiram a comunicação de massa e popular até então, o que permanece sendo uma realidade

\footnotetext{
4 Luiz Eduardo Wanderley era, na época, professor titular e ex-reitor da Pontifícia Universidade Católica de São Paulo. Ele é o autor do prefácio da obra Comunicação nos Movimentos Populares - A participação na construção da cidadania.
} 
para muitos representantes da esquerda brasileira, mesmo que ultrapassado na Academia.

Sobre comunicação popular, concluiu a pesquisadora:

Assim, há que se tomar a comunicação popular em seu entorno, onde, necessariamente, ela será captada não como uma ilha isolada, mas como algo que tem suas especificidades e se relaciona com a sociedade, convive com ela e dela usufrui mais amplamente. E também se verá que o popular não é homogêneo, porque é pluralista e histórico. Importa que ele seja apreendido em seu contexto, entendendo-se em seu interior a cultura. Desse modo, possivelmente não "demoniaremos" o massivo nem faremos pouco caso de seu potencial de influenciação, como também não "endeusaremos" ou menosprezaremos o popular. Ou seja, este não será tomado simplesmente em sua virtualidade revolucionária nem, por outro lado, só na perspectiva saudosista do folclórico, arcaico, melodramático e/ou massivo. Como a sociedade, a cultura não é algo estático. Em seu movimento, nas décadas de setenta e oitenta, ele tem sido reflexo não só da reprodução de valores e da criação e recriação de outros, mas também da introdução da utopia (Idem, p. 297).

Em 2001, a Fundação Rockefeller lançou um livro, fruto de reuniões realizadas por especialistas em comunicação, que apresentaram reflexões sobre a prática da comunicação para mudança social no novo milênio. O livro reúne uma coleção de cinqüenta histórias de casos, breves descrições de experiências de comunicação para a mudança social, selecionadas pelo enfoque participativo, ocorridas na África, Ásia e América Latina. Nele fica claro que não existe um modelo ideal para comunicação participativa e popular, pois cada experiência tem um caráter único, com aspectos positivos e negativos.

\section{A questão do Jornalismo Popular}

Como bem destacou Gomes (1990), o jornalismo articula-se com os veículos que veiculam suas mensagens, sem se identificar com eles. Por isso, o estudo do jornalismo não se reduz à mera análise de formas, mas compreende um processo amplo que vai desde a produção até o consumo. Definições, características e propostas para o Jornalismo Popular, Comunitário ou Alternativo devem partir, obrigatoriamente, do conceito de "jornalismo".

Sobre jornalismo, Marques de Melo (2003, p. 17) define: 
(...) Jornalismo é concebido como um processo social que se articula a partir da relação (periódica/oportuna) entre organizadores formais (editoras/emissoras) e coletividades (públicos/receptores), através de canais de difusão (jornal/revista/rádio/televisão/cinema) que asseguram a transmissão de informações (atuais) em função de interesses e expectativas (universos culturais ou ideológicos).

Em torno deste tema, faz-se, ainda, necessário diferenciar jornal de jornalismo, pois nem todo jornal circula com proposta jornalística. Há, ainda, vários tipos de jornalismo, entre eles, o popular, o alternativo, o comunitário, o radical, o engajado, o de serviços, o social, o cívico. Então, também é preciso diferenciar jornal popular de jornalismo popular. Carlos Eduardo Lins da Silva (1981) divide os jornais em jornais de prestígio, jornais populares e jornais políticos. Segundo análise de Gomes (Ibid., p. 55), nesta divisão apresentada por Lins da Silva

o "jornal popular" pertence à grande imprensa, mas se dirige ao chamado "povão", tem sua principal fonte de recurso na venda avulsa e quase não possui assinaturas. Sua primeira página atém-se somente ao inesperado, sensacional, inédito; busca o interesse imediato do leitor e visa criar empatia com este. Para ele, vale tudo para vender: sexo, esporte, crime. Tem muito título, fotos grandes e pouco texto. Entretanto, mesmo aqui essa denominação é problemática, por causa do conceito de "popular". O que é claro é que estes jornais (Notícias Populares, O Dia, etc.) diferem em muito dos chamados "jornais de prestígio" (Folha de São Paulo, O Estado de São Paulo, etc.).

E questiona:

Quando falamos de "jornalismo popular", não estamos nos referindo a este tipo de "jornal popular" que se contrapõe ao "jornal de prestígio" e ao "jornal político".

Portanto, o que significa realmente o "jornalismo popular"? O que torna um "jornal popular"? O conteúdo, a forma, o sujeito ou o destinatário? Para que um jornal seja "popular" será necessário que o sujeito (aquele que escreve) seja popular?[...]

A partir dessa polêmica, pergunta-se: Jornal popular e jornalismo popular são sinônimos? Entendemos que não, pois, apesar de semelhantes, possuem características próprias. Já nos anos 8o, Gomes alertava para o fato de existir uma enorme diversidade de publicações e boletins, que surgem no interior do movimento popular, nos meios estudantis, sindicais e no movimento operário, sendo problemática a uniformização de suas características em função das diferenças de contextos, objetivos e públicos desses periódicos. Também destacamos as inúmeras 
diferenças relativas à forma de produção desses periódicos e da formação cultural de seus produtores.

Através de organizações político-partidárias, sindicatos ou grupos de intelectuais identificados com as lutas das classes subalternas, diversos jornais desse tipo apareceram de forma irregular, durante, pelo menos, quase todo o decorrer deste século (GOMES, 1980, p. 76).

Durante o período de repressão no Brasil, foi difícil publicar os chamados jornais populares (conforme estabelecido por Lins da Silva). O período foi marcado, especialmente, pela imprensa de resistência, formada pelos jornais alternativos. Quanto a este fato, Lins da Silva relembra:

“(...) não só as organizações institucionalizadas (...) voltaram a publicar seus órgãos periódicos, como os trabalhadores, reunidos em seus bairros ou locais de trabalho, partiram para a edição de seus próprios jornais" (Ibid., p. 123).

Gomes também refuta a idéia de que o jornalismo popular se confunde com a imprensa alternativa e baseia-se em Sérgio Caparelli (1986) para afirmar que o termo "alternativa" refere-se a um trabalho de oposição à grande imprensa, a exemplo do que fizeram publicações como Movimento, Pasquim e Coojornal.

Para traçar um conceito de Jornalismo Popular, Gomes ampara-se em Lins da Silva (Ibidem) quando este diz:

Está claro que o conceito de jornalismo popular não pode ser confundido com o que vulgarmente muitos entendem como jornalismo consumido em larga escala por setores das classes populares e com uma temática voltada essencialmente para o noticiário sensacionalista de crimes, esportes ou sexo. Também não se aproxima do conceito de 'imprensa comunitária', como foi empregado por autores como Morris Janowitz (p. 52)”.

No tempos atuais, os jornais populares sofreram alterações em suas propostas editoriais. No ano 2000, a Rede Brasil de Comunicação, empresa líder em seu segmento no mercado do Rio Grande do Sul, lançou, em Porto Alegre o jornal Diário Gaúcho, direcionado a uma população de baixa renda e reduzido grau de instrução, com ênfase na cobertura de temas locais e prestação de serviços. A 
publicação, com 138 mil exemplares 5 , obteve grande sucesso junto ao público alvo e hoje é referência para quem estuda "jornais populares", como é identificado o DG por seus produtores. Ele, no entanto, não tem as características apresentadas por Lins da Silva (Idem) ao definir "jornalismo popular", apesar de dar ênfase ao noticiário que envolve, crime, esporte e sexo, porém, não de forma sensacionalista.

Conforme Amaral (2006),

os jornais auto-intitulados populares baseiam-se na valorização do cotidiano, da fruição individual, do sentimento e da subjetividade. Os assuntos públicos são muitas vezes ignorados; o mundo é percebido de maneira personalizada e os fatos são singularizados ao extremo. O enfoque sobre grandes temas recai sobre o ângulo subjetivo e pessoal. O público leitor, distante das esferas de poder, prefere ver sua cotidianidade impressa no jornal, e a informação é sinônimo de sensação e da versão de diferentes realidades individuais em forma de espetáculo.

O jornal resgata a cultura de almanaque e seu espírito lúdico e de serviço. O calendário, as festas e as fases da lua trazem elementos da literatura popular. Assim como os almanaques, o jornal publica receitas de medicina popular, casos sobrenaturais, indicações astronômicas, anedotas, horóscopo, passatempos, concursos e situações cômicas da vida cotidiana - constituindo-se ao mesmo tempo num setor de reclamações, num guia de serviços, e nu manual de aconselhamentos (p. 57-58).

A respeito da possível comparação entre as imprensas popular e comunitária, Marques de Melo afirma:

[...] uma imprensa só pode ser considerada comunitária quando se estrutura e funciona como meio de comunicação autêntico de uma comunidade. Isto significa dizer: produzida pela e para a comunidade (1979, p. 112).

Em virtude dos problemas sócio-estruturais, Marques de Melo acredita que não existe imprensa comunitária no Brasil. Existe tentativa de imprensa comunitária.

Sobre essa conceituação, Gomes (1990, p. 62) alerta:

Pelo que Marques de Melo aponta como pressuposto para a imprensa comunitária, depreende-se que ele identifica esta com a imprensa popular, muito embora não o explicite. Vale recordar que o que torna uma comunicação popular - na opinião de alguns autores - parece ser o que torna uma imprensa comunitária - na opinião de José Marques de Melo.

${ }^{5}$ AMARAL, Márcia Franz. Jornalismo Popular, São Paulo: Contexto, 2006. 
Lins da Silva (Op. cit., p. 40) identificou três tipos ou espécies de jornalismo popular, aos quais o Diário Gaúcho não se enquadra em nenhum deles:

1. aqueles que defendem as classes trabalhadoras, mas estas não os produzem nem são os destinatários principais;

2. aqueles que defendem os interesses das classes trabalhadoras, sendo estas os destinatários principais, mas não são elas que o produzem;

3. aqueles que defendem os interesses das classes trabalhadoras são por elas produzidos e a elas se destinam.

Nos últimos dez anos, no entanto, estabeleceu-se, pelo menos, em Porto Alegre, uma imprensa comunitária, através dos jornais de bairro, produzida por jornalistas que atendem tanto as características levantadas por Lins da Silva, acima citadas, quanto as apresentadas por Marcondes Filho (1986):

Um jornal comunitário é elaborado por membros de uma comunidade que procuram através dele obter mais força política, melhor poder de barganha, mais impacto social, não para alguns interesses particularizados (anunciantes, figuras proeminentes), mas para toda a comunidade que esteja operando o veículo. [...] Qualquer comunidade pode articular-se politicamente e, aí, utilizarse de um jornal comunitário onde sua voz ganhe mais eco, suas reivindicações cheguem muito mais além do que seu - em geral pequeno - território. Com esse tipo de jornalismo, como o jornal de minorias sexuais, sociais e étnicas, essas comunidades podem romper com o gueto a que estão submetidas pelos critérios de marginalização predominantes na sociedade (p. 161-162).

O Diário Gaúcho seria aquele que ajuda a população de baixa renda e de baixa instrução a resolver os problemas do cotidiano, no que tange aos serviços públicos, através da publicação de notícias que mostrem o dia-a-dia dessa população, sendo ela o destinatário principal. Fazer com que esse segmento compreenda os motivos sociais, políticos, econômicos, culturais, entre outros, que determinam a desigualdade social e as injustiças, bem como protestar, mobilizar e lutar contra essa situação não é objetivo do Diário Gaúcho. Portanto, também não é correto chamá-lo de jornal comunitário.

Na mesma direção de Lins da Silva e Marcondes Filho, outras características do jornal popular e do comunitário foram listadas por Callado (1985): 
[...] os problemas diários da comunidade ${ }^{6}$ só chegam às páginas dos grandes jornais e revistas quando ocorrem catástrofes.

[...] não é possível a um grande jornal, que é uma empresa com finalidade de lucro, tratar dos problemas de cada pequena comunidade, de cada bairro, cada cidade. Para isso é que tem que existir a imprensa comunitária, a mais importante alternativa, no momento atual do Brasil, à imprensa monopolizadora.

[...] o jornal comunitário é muito mais que um órgão de informação; é um instrumento de mobilização.

De acordo com Gomes (1990), manual produzido pela Comissão Evangélica Latino-americana de Educação Cristã (CELADEC, 1984), editado pelas Edições Paulinas, "situa o jornalismo popular como alternativa aos grandes meios".

Frente ao Jornalismo dos opressores, a criatividade dos setores populares gera uma alternativa própria: O JORNALISMO POPULAR. Por setores populares se entende o conjunto de classes e camadas sociais que procuram, num determinado momento histórico, mudar progressivamente a sociedade e criar as condições propícias para levar até o fim essa mudança."

"[...] As informações veiculadas nesses jornais representam os interesses dos oprimidos, colocando sua prática social e também as alternativas de sua luta pela libertação (Idem, p. 134).

No manual da CELADEC (Ibidem) consta que "no jornalismo popular, emissores e receptores são sujeitos. Trata-se de um jornalismo feito pelo povo e para o povo”. A informação, o diálogo, a educação, a organização e a mobilização são funções do jornalismo popular. Baseado no referido material, Gomes (1990) apresenta as características que considera representativas do Jornal Popular7: "Um jornal popular nunca é um fim em si mesmo; o jornal popular é um produto da comunidade; o jornal popular é um instrumento de trabalho comunitário, reflete a problemática da comunidade no sentido global”.

Deste modo, o jornal popular trata de notícias, comentários, editorial, entrevistas, pesquisa, titulação, etc. e aceita obedecer as leis jornalísticas. Mas, podemos observar que até hoje não há consenso em torno das características e

\footnotetext{
${ }^{6}$ Os problemas diários da comunidade estão presentes no dia a dia das páginas dos jornais populares ou comunitários, por isso representam uma característica dos mesmos, conforme Callado.

7 Fica claro que Gomes adota para seus estudos o conceito de jornalismo popular estabelecido por Marques de Melo, por Ana Arruda Callado e pelo manual da Celadec.
} 
definição de jornalismo popular, jornalismo alternativo, jornal popular, jornal comunitário, jornalismo comunitário, jornal alternativo, pois práticos e teóricos vêm empregando os termos para diferentes situações.

Verificamos que as propostas feitas por diferentes pesquisadores se enquadram para algumas experiências, mas não para todas. Assim, não é possível generalizá-las. Propõe-se que sejam feitos estudos em maior profundidade, a partir dos jornais existentes em circulação, considerando a intenção dos produtores e dos receptores das diferentes publicações, além, é claro, do conteúdo divulgado.

A indefinição em torno dos termos pôde ser constatada em 1996, quando a Universidade Gama Filho realizou o II Encontro de Comunicação Social - Gamacom - Ideologia \& Poder da Comunicação Alternativa. Nele, vários tópicos sobre o tema foram debatidos e dissertados, deixando claro que ainda não havia consenso em torno das expressões acima citadas, pois os exemplos apresentados misturavam características de popular com comunitário, com alternativo, com informativo e assim por diante.

Podemos, no entanto, adiantar que atualmente existe uma tendência conciliatória por parte dos pesquisadores em torno do conceito de "imprensa alternativa", compreendida como aquela que pratica um jornalismo à margem da chamada imprensa convencional. Seriam os jornais alternativos a uma grande imprensa. Uma alternativa, uma opção a mais dentre as mídias já existentes.

Também é consenso ser fundamental a presença de uma imprensa alternativa no Brasil.

Uma imprensa viva, das chamadas minorias que, na verdade, são maiorias, como é o caso das mulheres, que fazem parte de $52 \%$ da população; ou dos negros; ou dos gays, que também podem entrar neste contexto. As minorias efetivas precisam ter uma voz, coisa que o Brasil já teve e hoje não tem mais, ou tem em menor escala. As minorias estão muito mal servidas de imprensa alternativa, uma imprensa que abra portas para as suas manifestações. A saída, portanto, é ativar a circulação das idéias, procurando dentro da comunidade os assuntos que são, ou deveriam ser, verdadeiramente notícia. (PINHEIRO, 1996, p. 64).

Segundo visão de Pinheiro para imprensa alternativa, que considera uma imprensa que abre portas para as manifestações populares, ativando a circulação das 
idéias e procurando dentro da comunidade os assuntos que são, ou deveriam ser, verdadeiramente notícia, destacamos a existência de alguns jornais que realmente dão voz às minorias e às classes despossuídas de poder político e econômico, como um grupo de jornais de bairro de Porto Alegre, alguns jornais do interior e alguns jornais de segmentos, como o cultural e ambiental8. Todos eles têm como diferencial, desconsiderando exceções, o fato de refletirem a realidade da comunidade para qual se dirigem, bem como objetivarem informar, dialogar, educar, organizar e mobilizar a comunidade em torno de causas que visam ao bem comum.

Nem sempre todas essas características são visíveis - ou possíveis - ao mesmo tempo, mas elas balizam a atividade dos jornalistas e líderes comunitários engajados neste setor9. Além disto, amparam-se nos três pilares estabelecidos por Beltrán para definição da comunicação horizontal: reconhecem o direito de todos receberem mensagens (os jornais são distribuídos gratuitamente, casa por casa), aceitam publicar todos os textos enviados pela comunidade (desde que não firam legislação vigente) e admitem participação da comunidade na transmissão e produção do material jornalístico. Podemos defini-los, então, como jornais (e jornalistas) socialmente engajados, o que entendemos ser um mérito e não uma desqualificação.

\footnotetext{
${ }^{8}$ Sobre o assunto, leia-se artigos e livros de Beatriz Dornelles, citados nas referências. 9 Aprofundamento do tema em Teoria do Jornalismo - Identidades brasileiras, de José Marques de Melo, 2006 e Mídia cidadã - Utopia brasileira, organizado por José Marques de Melo, Maria Cristina Gobbi e Luciano Sathler, 2006.
} 


\section{Referências bibliográficas}

AMARAL, Márcia Franz. Jornalismo Popular. São Paulo: Contexto, 2006.

BELTRÁN, Luiz Ramiro. Adeus a Aristóteles: comunicação horizontal. Comunicação \& Sociedade, São Bernardo do Campo, IMS, ano III, nº 6, set. 1981.

BERGER, Christa. A Comunicação Emergente: Popular e/ou Alternativa no Brasil. Porto Alegre: UFRGS, 1989.

CALLADO, Ana Arruda \& DUQUE ESTRADA, Maria Ignez. Como se faz um jornal comunitário. Petrópolis, Vozes/Ibase, 1985.

CAPARELLI, Sérgio. Comunicação de massa sem massa. $3^{\text {a }}$ ed., São Paulo: Summus, 1986.

CELADEC. Jornalismo popular. São Paulo: Paulinas, 1984.

DORNELLES, Beatriz. Imprensa comunitária:jornais de bairro de Porto Alegre. In: Mídia, Imagem \& Cultura, HAUSSEN, Doris Fagundes (org.). Coleção Comunicação, Porto Alegre:EDIPUCRS, 2000.

, Beatriz. Jornalismo "Comunitário” em cidades do Interior. Porto Alegre: Sagra Luzzatto, 2004.

, Beatriz \& BIZ, Osvaldo. Jornalismo Solidário. Porto Alegre, Evangraf, 2006.

ESPINOSA, Felipe. Pistas para la comunicación popular. México: Christus, 1978.

FESTA, Regina. Comunicação popular e alternativa. A realidade e as utopias. São Bernardo do Campo: IMS, 1984.

FESTA, Regina e LINS DA SILVA, Carlos Eduardo (orgs.). Comunicação Popular e Alternativa no Brasil. São Paulo: Edições Paulinas, 1986.

GIMÉNEZ, Gilberto. Notas pata uma teoria de comunicación popular. México: Christus, 1978.

GOMES, Pedro Gilberto. O Jornalismo Alternativo no projeto popular. São Paulo: Paulinas, 1990.

PARDO, Hérnan Martinez. El contexto de la comunicación popular y la comunicación alternativa. Cultura popular. Lima: CELADEC, abr. 1982.

KAPLUN, Mario. Hacia nuevas estrategias de comunicación en la educación de adultos. Santiago, OREAL/ Unesco, 1983.

LASSWELL, H. The Structure and Functions of Communication in Society. In: The Communication of Ideas. Nova York: Harper, 1948.

LINS DA SILVA, Carlos Eduardo. Jornalismo popular no Rio Grande do Norte. In: Comunicação \& Sociedade, São Bernardo do Campo, IMS, 1981.

MARCONDES FILHO, Ciro. Quem manipula quem? Petrópolis: Vozes, 1986.

MARQUES DE MELO, José. Imprensa comunitária no Brasil. Comunicação \& Sociedade, Cortez e Moraes, 1979. 
e BRITTES, Juçara Gorski. A Trajetória Comunicacional de Luiz Ramiro Beltrán. São Paulo: Umesp, 1998.

. Jornalismo Opinativo - Gêneros opinativos no jornalismo brasileiro.

Campos do Jordão: Editora Mantiqueira, 2003.

. A opinião no jornalismo brasileiro. Petrópolis: Vozes, 1985.

. Comunicação comunitária. A imprensa comunitária no Brasil. In:

Comunicação \& Libertação. Petrópolis: Vozes, 1981.

. A emergência de um novo jornalismo católico. Comunicação: teoria e política. São Paulo: Summus, 1985.

. Comunicação \& libertação. Petrópolis: Vozes, 1981.

. Para uma leitura crítica da comunicação. São Paulo: Paulinas, 1985.

. Teoria do Jornalismo - Identidades brasileiras. São Paulo: Paulus, 2006.

; GOBBI, Maria Cristina e SATHLER, Luciano (orgs.) Mídia cidadã Utopia Brasileira. São Bernardo do Campo: Universidae Metodista de São Paulo, 2006.

PAIVA, Raquel. O Espírito Comum. Comunidade, mídia e globalismo. Petrópolis: Vozes, 1998.

PARDO, Hérnan Martinez. La comunicación popular en el NOMIC. UNDA/AL Comunicación, Quito, 1982.

PERUZZO, Cecilia Maria Krohling. Comunicacao nos Movimentos Populares - A participação na construção da cidadania. Petrópolis: Vozes, 1999.

. Comunicación popular. Comunicación cristina: desafío y cambio. Buenos Aires, WACC, 1981. (mimeo).

. El contexto de la comunicación popular y la comunicación alternativa. Cultura popular, Lima, CELADEC, abr. 1982.

MATA, Maria Cristina. Comunicación popular y comunidad. Comunicación cristina: desafio y cambio. Buenos Aires: WACC, 1981 (mimeo).

MOMESSO, Luiz Anastácio. A emergente imprensa na periferia de São Paulo. In: Comunicação \& Sociedade, Cortez e Moraes, mar. 1981.

PINHEIRO, Flávio. Jornalismo Alternativo; Alternativa do Jornalismo. In: Memórias II Gamacom - Ideologia \& Poder da Comunicação Alternativa, Universidade Gama Filho, 1996.

TERRERO, José Martinez. Iglesia y Comunicación popular. UNDA/AL Comunicación, Quito, nov. 1982.

VANDERHOFF, Francisco. Evangelización y comunicación popular: situación, posibilidades y límites de la comunicación popular en América Latina. Christus, dez. 1978. 